\title{
AVALIAÇÃO DOS FATORES HIGIÊNICOS E MOTIVACIONAIS NO SETOR DE FOOD SERVICE NO MUNICIPÍO DE SALGUEIRO-PE
}

\author{
Islaneide Figueredo dos Santos (UNIVERSIDADE DE PERNAMBUCO) Figueredolanny645@gmail.com \\ Eryka Fernanda Miranda Sobral (UNIVERSIDADE DE PERNAMBUCO) Eryka.sobral@upe.br \\ Tiago Silveira Machado (UNIVERSIDADE DE PERNAMBUCO) Tiago.machado@upe.br \\ Bartira Pereira Amorim (UNIVERSIDADE DE PERNAMBUCO) Bartira.amorim@upe.br \\ Fagner José Coutinho de Melo (UNIVERSIDADE DE PERNAMBUCO) Fagner.melo@upe.br
}

\section{Resumo}

As pessoas são motivadas diariamente, procurando satisfazer suas ideias e atingir suas metas, é nesse contexto que muitos estudiosos buscam respostas através de teorias elaboradas sobre motivação, na tentativa de compreender o que é capaz de motivar e satisfazer o ser humano. No contexto organizacional, ter funcionários motivados é a missão primordial das organizações, e isto tem sido objeto de estudo ao longo dos anos, sendo assim a presente pesquisa teve por objetivo avaliar os fatores motivacionais e higiênicos por meio da teoria dos dois fatores de Herzberg, com aplicação de um questionário com 44 perguntas divididas em motivacionais e higiênicas no setor de food service. O instrumento de coleta de dados foi aplicado a 10 funcionários dividido em três restaurantes no município de Salgueiro-PE. Os três restaurantes juntos possuíam 15 funcionários, porém 5 funcionários se abstiveram a responder, desta maneira a amostra foi reflexo do ambiente estudado. Neste trabalho concluise que os funcionários não possuem oportunidades de crescimento, foi constatado que parte dos funcionários não sabem o que é um plano de carreiras, porque as empresas, como restaurantes não possuem devido ao número menor de funcionários.

Palavras-Chaves: Fatores motivacionais; Fatores higiênicos; Motivação; Pessoas; Food service; Gestão estratégica.

\section{Introdução}

A motivação humana é a ferramenta chave para o sucesso de qualquer empresa, embora haja ainda questionamentos sobre o que realmente motiva as pessoas, e é exatamente o que os gestores tentam compreender com o intuito de fazer com que os colaboradores se sintam parte fundamental da empresa (KLEIN; MASCARENHAS, 2014). A motivação é o impulso que estimula as pessoas a agir, que surge através de uma necessidade, assim, cada indivíduo dispõe de motivações gerada por necessidades distintas (BERGAMINI; CODA, 1990).

Ainda sobre a importância da motivação, é válido ressaltar que os gestores precisam atentar ao o que é capaz de impulsionar as pessoas a terem desempenhos positivos dentro das organizações (ALBUQUERQUE et al., 2019). Os incentivos desenvolvidos dentro das organizações impulsionam os colaboradores a motivarem uns aos outros, gerando assim um ciclo motivacional, mas tendo como objetivo crescimento pessoal e organizacional (FERNANDES, 2014). 
O salário não é um fator de motivação quando analisado de forma isolada, isso porque o salário não gera satisfação ao funcionário, é apenas a recompensa justa pelo o seu trabalho (PONTES, 2015).

Conforme Chiavenato (2014) a satisfação é resultado do êxito alcançado no processo motivacional, e a motivação está relacionada com o comportamento direcionado para o alcanço de metas ou incentivos. Desta forma, as pessoas são impulsionadas por motivações tanto internas como externas, oferecidas no seu ambiente de trabalho. Quando se trata do ambiente de trabalho o grau de motivação deve estar relacionado ao clima organizacional, com isso o comportamento dos funcionários é influenciado através do ambiente que convivem (TEJADA, 2013).

Quando se trata de MPEs (Micro e Pequenas Empresas) até 2022 o Brasil contará com mais de 17,7 milhões de empreendimentos mesmo diante da crise financeira, sendo este cenário propicio (SEBRAE, 2018). No Brasil existem 6,4 milhões de estabelecimentos, sendo que 99\% são MPES, respondendo por 52\% de empregos (SEBRAE, 2018). De acordo com (BENDÔ, 2018) o crescimento econômico do país depende das MPEs, com isso, é importante que as empresas saibam superar as dificuldades e conseguirem sobreviver atuando no mercado. O setor de serviços tem crescido nos últimos anos, destacando se o ramo de restaurantes, conforme a Associação Brasileira de Bares e Restaurantes (ABRASEL) o setor tem gerado 450 mil empregos por ano (SEBRAE, 2019). Os bares e restaurantes são responsáveis por grande parte de serviços oferecidos no País, o segmento alimentício tem trazido segurança, conforto, praticidade, e dentre outros fatores os bares e os restaurantes de qualidade, levam o cliente a aderir os serviços (SEBRAE, 2019).

Desta maneira o presente trabalho teve como objetivo avaliar os fatores higiênicos e motivacionais dos funcionários no setor de food service utilizando a Teoria de Herzberg, através da aplicação de um questionário em três restaurantes no município de Salgueiro. A amostra selecionada foi de 10 funcionários de empresa estudo de caso. Os três restaurantes juntos possuíam 15 funcionários, porém 5 funcionários se abstiveram a responder, desta maneira a amostra foi reflexo do ambiente estudado.

Ao longo das pesquisas sobre os fatores que influenciam as pessoas no seu ambiente de trabalho, Herzberg desenvolveu a teoria dos dois fatores baseado em pesquisas feita em onze indústrias de Pittsburgh, com duzentos engenheiros e contadores. As pesquisas foram feitas através de entrevistas sobre o que os deixavam satisfeitos e insatisfeitos no trabalho (LO et al., 2016). Herzberg conclui que a insatisfação tinha características totalmente diferentes do 
que conduzia a satisfação, desta forma, ele definiu o a teoria dos dois fatores como: fatores higiênicos ou extrínsecos e fatores motivacionais ou intrínsecos (ROBBINS, 2005).

\section{Revisão da literatura}

Esta seção teve por objetivo apresentar os conceitos que irão nortear esta pesquisa como: teoria dos dois fatores e food service.

\subsection{Teoria dos Dois Fatores de Frederick Herzberg}

Na década de 1950 foi desenvolvida a teoria dos dois fatores de Frederick Herzberg que serviu de base para as pesquisas que foram realizadas com 203 funcionários entre engenheiros e contadores com o objetivo de identificar nos trabalhadores o que lhes faziam bem ou mal no ambiente de trabalho, com isso, Herzberg revelou por meio dos resultados da pesquisa dois conjuntos de fatores relacionados à motivação e compreendeu que o resultado positivo estava relacionado com o bem estar dos trabalhadores no emprego, no entanto, as respostas negativas mostravam a insatisfação dos empregados (KHALID, 2014). Os fatores estão apresentados no Quadro 1.

QUADRO 1: Fatores Higiênicos e Motivacionais

\begin{tabular}{|c|c|}
\hline FATORES HIGIÊNICOS & FATORES MOTIVACIONAIS \\
\hline Salários & Reconhecimento \\
Status & Trabalho em Si \\
Condição de Trabalho & Responsabilidade \\
Vida pessoal & Realização \\
Relações interpessoais & Possibilidade de Crescimento \\
Políticas da Empresa & Avanços/Promoções \\
Supervisão & \\
\hline
\end{tabular}

Fonte: Adaptado de Herzberg (1987).

Conforme Albuquerque et al. (2017) os fatores que conduzem a satisfação no trabalho são denominados de higiênicos, pois estão relacionados com as condições em que é realizado o trabalho. Os fatores motivacionais estão diretamente ligados com o trabalho ou a tarefa, influenciando diretamente a produtividade dos colaboradores.

Ao longo da pesquisa, Herzberg et al., (1959) progrediu nos estudos de Maslow, e utilizou os aspectos mais voltados para o trabalho, desta maneira, ele considerou que as necessidades como de segurança, fisiológicas e sociais fazem parte dos fatores higiênicos, se não atendem a satisfação do indivíduo, logo gera insatisfação, e se estiverem satisfeitos, não tem satisfação. Por outro lado, as condições de trabalho inadequado, salário, benefícios podem trazer insatisfação e se atendem as condições, podem não motivar as pessoas. 
Ainda conforme Herzberg et al. (1959), necessidades como de auto realização e estimas fazem parte dos fatores motivacionais, isso porque podem produzir efeitos mais longos nas pessoas e envolvem profundos sentimentos de satisfação. Assim, os fatores motivacionais ou intrínsecos tendem a aumentar a satisfação nas pessoas, porém na ausência ou quando são precários acabam provocando a falta de satisfação na pessoa (DOMINGOS, BARBOSA, 2016).

É importante remover os fatores de insatisfação e procurar medidas que satisfaçam, observando o ambiente de trabalho que causam a insatisfação e atendendo as pequenas necessidades como: instalar aparelhos de ar condicionado, aumento de salário, melhorar condições de trabalho proporcionando lazer aos funcionários, mesmo não retirando as fontes de insatisfação, é preciso inserir fatores de satisfação (ALBUQUERQUE et al., 2019).

\subsection{Food Service}

O conceito de Food service vai muito além de realizar refeições fora do lar, no que refere à produção, equipamentos e prestação de serviços tudo isto faz parte desse segmento de mercado, tendo uma grande importância na gastronomia, tendo em vista que os brasileiros veem criando o hábito de comer fora do lar, sendo assim, o mercado é movimentado não apenas na aquisição da refeição fora do lar, mas em casa também através do serviço de entrega (MEDEIROS, 2009).

É um termo que abrange toda a indústria de alimentos e bebidas, desde quando elas são produzidas e distribuídas até seu preparo e serviço ao cliente, com o diferencial de que está relacionado a refeições feitas fora de casa, como em restaurantes, lanchonetes e afins (HOBER et al., 2015).

\section{Metodologia}

Para a Fonseca (2002) a metodologia é o estudo da organização, dos caminhos a serem percorridos, é um estudo sistemático, pesquisa, investigação. Foi utilizada a abordagem da pesquisa qualitativa, porque oferece maior liberdade para relatar toda a pesquisa durante o processo (FONSECA, 2002). A pesquisa foi classificada, quanto ao objetivo, como exploratória uma vez que a temática ainda é incipiente. A pesquisa foi classificada como do tipo survey uma vez que houve a necessidade de questionar os funcionários dos restaurantes.

Para a realização do estudo, foi desenvolvido um questionário adaptado de Medeiros (2009). Na primeira parte estão as questões relacionadas ao perfil do entrevistado. Na segunda parte, foi elaborado um questionário com 44 perguntas com respeito aos fatores motivacionais 
(trabalho em si, realização, reconhecimento, progresso profissional, responsabilidades, desenvolvimento pessoal, enriquecimento de cargo) e dos fatores higiênicos (Condições de trabalho, políticas administrativas, salário, relacionamento interpessoal, segurança, status, competência do supervisor). O instrumento de coleta de dados foi aplicado a 10 funcionários de três restaurantes no município de Salgueiro-PE. Os três restaurantes juntos possuíam 15 funcionários, porém 5 funcionários se abstiveram a responder, desta maneira a amostra foi reflexo do ambiente estudado.

\section{Resultados}

Para a coleta dos dados, foi aplicado um questionário entre 10 funcionários, de diversos setores de um restaurante, com o objetivo de conhecer a organização, e avaliar os fatores motivacionais e higiênicos utilizando a teoria de Herzberg (1987). A Tabela 1 a seguir apresenta informações da amostra: Por sexo, faixa etária, escolaridade, e tempo de trabalho.

\begin{tabular}{|c|c|c|}
\hline Itens & Características & $\%$ \\
\hline \multirow{2}{*}{ Gênero } & Feminino & 80 \\
\hline & Masculino & 20 \\
\hline \multirow{3}{*}{$\begin{array}{l}\text { Faixa } \\
\text { (Anos) }\end{array}$} & $<25$ & 10 \\
\hline & 25 A 45 & 90 \\
\hline & $>45$ & 0 \\
\hline Escolaridade & Ensino Médio Completo & 100 \\
\hline Tempo & Até 5 anos & 80 \\
\hline Trabalho (Anos) & De 6 a 10 anos & 20 \\
\hline
\end{tabular}

A partir da Tabela 1 foi possível verificar que a amostra é predominante do sexo feminino (80\%). Com relação a faixa etária verificou-se que os funcionários possuem idade entre 25 e 45 anos (90\%) e apenas 10\% possuía idade menor que 25 anos. Quanto a escolaridade 100\% da amostra possuíam ensino médio completo. No que diz respeito a tempo de serviço, $80 \%$ da amostra estudada possui até 5 anos de empresa e $20 \%$ dos funcionários possui entre 6 e 10 anos de empresa.

\subsection{Fatores Motivacionais}

Os fatores motivacionais são caracterizados como os fatores intrínsecos relacionados às atividades e conteúdo do cargo (ALBURQUERQUE et al., 2017). Os fatores motivacionais estudados nessa seção são o trabalho em si, realização, reconhecimento do desempenho, 
progresso profissional, maior responsabilidade, desenvolvimento pessoal e enriquecimento do cargo.

Os fatores motivacionais foram avaliados segundo a média dos funcionários, para média menor que 4, os funcionários foram considerados muito insatisfeitos, para média entre 4 e 6 os funcionários foram considerados insatisfeitos, para média entre 6 e 7 os funcionários não foram considerados insatisfeitos e nem satisfeitos, para média entre 7 e 8 os funcionários foram considerados satisfeitos e para média acima de 8 os funcionários foram considerados muito satisfeitos. Na Tabela 2 foi apresentada as médias gerais para os seguintes fatores motivacionais da organização estudada.

TABELA 2- Média geral dos Fatores Motivacionais

\begin{tabular}{lcc}
\hline \multicolumn{1}{c}{ Fatores motivacionais } & $\begin{array}{c}\text { Média } \\
\text { Geral }\end{array}$ & Classificação do fator \\
\hline Trabalho em si & 8,45 & Muito Satisfeito \\
Realização & 6,65 & Nem insatisfeitos e nem satisfeitos \\
Reconhecimento do desempenho & 5,86 & Insatisfeito \\
Progresso profissional & 4,0 & Insatisfeito \\
Maior responsabilidade & 8,46 & Muito Satisfeito \\
Desenvolvimento pessoal & 6,55 & Nem insatisfeitos e nem satisfeitos \\
Enriquecimento do cargo & 5,85 & Insatisfeito \\
\hline \multicolumn{2}{c}{}
\end{tabular}

A partir da Tabela 2 foi possível observar que o fator trabalho em si - como é realizado as tarefas e interesses dos colaboradores em produzir com qualidade, a pontuação indicou satisfação e motivação (9,5 e 7,4 de média das questões 1 e 2) no entanto, é necessário enfatizar mais ainda os fatores ligados ao trabalho em si, resultando em um trabalho mais produtivo e capaz de gerar prazer em realiza-lo (PERRY; PORTER, 1982).

No que se refere ao fator realização, na questão 3 obteve a média de 9,7 demonstrando que eles tem um enorme interesse em realizar novas atividades, na questão 4 a média foi de 8,1 mostrando o quanto utilizam a criatividade, percebe-se uma pequena diferença, pois é necessário que haja incentivos para que os funcionários coloquem em ação o uso da criatividade para melhor desempenho da organização. Na questão 5 , foi questionado se o colaborador tem interesse em outros departamentos, $80 \%$ afirmaram que sim e $20 \%$ não optaram. As questões 6 e 7 obtiveram média de 6 e 2,8, deixando claro que a pouca interação com outras atividades e deixam a desejar o interesse para possibilidades em ajudar outras pessoas.

Sobre o reconhecimento, foi notório a insatisfação com base nas médias (7,6; 5,8 e 4,2) das questões $(8,9$ e 10) pois demonstram total indignação por não serem reconhecidos pelo o 
desempenho, no entanto a mais reconhecimento por parte dos colegas do que pelo o líder, que é essencial para o progresso profissional.

A respeito do progresso profissional, questões (11, 12, 13, 14 e 43) obtiveram médias baixas, isso porque muitos desconheciam o plano de carreira, e acabavam respondendo de forma aleatória. A questão 43 foi respondida de maneira avulsa, pois se não sabiam se tinha plano de carreira na empresa, como poderiam almejar carreira profissional.

No fator responsabilidade, a média das questões $(15,16$ e 17) foram $(8,9 ; 7,9$ e 8,6) mostrando assim, que os trabalhadores estão motivados a exercerem suas responsabilidades no ambiente de trabalho com qualidade. É fundamental que o líder motive e incentive os funcionários a manter esta responsabilidade, e adquirir conhecimentos necessários para que as tarefas sejam feitas com total preparo.

No quesito desenvolvimento pessoal, a média das questões (18 e 19) obteve $(5,9$ e 7,2) revelando que os colaboradores estão desmotivados para aceitarem dificuldades fora da rotina, preferem atuar num ambiente conhecido. Por outro lado, eles possuem um forte interesse em aumentar produtividade, significa que estão sendo motivados, o que resulta em ótimos resultados para a organização.

A respeito do enriquecimento do cargo, as questões (20 e 21) expressaram principalmente que raramente há novas tarefas com grau de dificuldades. A respeito da execução de tarefas com autonomia, obtivemos respostas com satisfação (média das questões 20 e 21 (5,7 e 6). Um ambiente de trabalho que traz satisfação aos empregados tende a produzir e aumentar a produtividade com excelência.

\subsection{Fatores Higiênicos}

Os fatores higiênicos são considerados fatores extrínsecos relacionados às condições físicas do ambiente, salário, benefícios, políticas, clima organizacional, oportunidades, etc. (ALBURQUERQUE et al., 2017). Os fatores higiênicos estudados nessa seção foram condições de trabalho, políticas administrativas, salários, relacionamento interpessoal, segurança, status e competência do supervisor.

Esses fatores foram avaliados segundo a média dos respondentes, para média menor que 4, os funcionários foram considerados muito insatisfeitos, para média entre 4 e 6 os funcionários foram considerados insatisfeitos, para média entre 6 e 7 os funcionários não foram considerados insatisfeitos e nem satisfeitos, para média entre 7 e 8 os funcionários foram considerados satisfeitos e para média acima de 8 os funcionários foram considerados muito 
satisfeitos. Na Tabela 3 foram apresentadas as médias gerais para os seguintes fatores higiênicos da organização estudada.

TABELA 3-Média geral dos Fatores Higiênicos

\begin{tabular}{lcc}
\hline \multicolumn{1}{c}{ Fatores Higiênicos } & $\begin{array}{l}\text { Média } \\
\text { geral }\end{array}$ & Classificação do fator \\
\hline Condições de trabalho & 8,9 & Muito satisfeito \\
Políticas administrativas & 8,225 & Muito satisfeito \\
Salários & 7,35 & Satisfeito \\
Relacionamento interpessoal & 8,63 & Muito Satisfeito \\
Segurança & 6,66 & Nem insatisfeitos e nem satisfeitos \\
Status & 7,05 & Satisfeito \\
Competência do supervisor & 9,2 & Muito Satisfeito \\
\hline
\end{tabular}

Fonte: Os autores (2020)

No fator condições de trabalho foi observado que os respondentes demostraram um alto grau de satisfação com as condições de trabalho, localização, acesso físico a outros setores, as questões $(22,23,23,25,26$ e 42) obtiveram média de 8,9 deixando claro total satisfação com o ambiente de trabalho.

As políticas administrativas elencadas nas questões $(27,28,29$ e 30$)$ obteve média entre $(8,8$; 8,$9 ; 7,3$ e 7,9), isso só demonstra que uma boa parte dos funcionários estavam satisfeitos com as diretrizes administrativas da empresa.

O fator salário teve média (7,9 e 6,8) nas questões (31 e 32) demonstraram um grau médio de satisfação, visto que a maioria sofre variações no salário, sem recompensas e benefícios, não tendo plano de cargos e salários. Por ser restaurantes, alguns respondentes possuem o mesmo cargo, o que acaba não sofrendo alterações salarias.

A respeito do relacionamento interpessoal, as questões $(33,34$ e 35$)$ obteve média de $(8,7 ; 8,6$ e 8,6) esse resultado só mostra que os funcionários se sentem satisfeitos por conviverem num ambiente de trabalho em que há harmonia e interação entre as equipes.

Sobre o fator segurança nas questões (36, 37 e 44) com média (6; 6 e 8) no quesito 44 foi constatado apenas um registro de 1 acidente, trazendo insatisfação ao respondente pelo o fato da empresa não ter investimentos que assegurem a segurança do setor onde ele trabalha. Nos demais, a média mostra um grau de satisfação, isso porque dependendo do setor da empresa, há um grau mais elevado de segurança. Investir em segurança é importante, pois além de trazer segurança para o ambiente de trabalho, evita também acidentes rotineiros do dia a dia.

No quesito status, as questões (38 e 39) obtiveram média de $(5,9$ e 8,2). A questão 38 mostrou claramente a insatisfação por parte dos respondentes sobre o quesito reconhecimento por parte da chefia. Enquanto a outra questão traz satisfação, pois os respondentes demostraram 
estarem satisfeitos pelo o cargo que possuem. Reconhecimento é importante para manter os bons funcionários produzindo cada vez mais com qualidade, é importante que o líder saiba reconhecer o bom trabalho que é realizado pelos seus funcionários.

A respeito da competência do Supervisor teve duas questões (40 e 41) com média de $(9,7$ e 8,7) com base nesses resultados ficou evidente que os funcionários se sentem satisfeitos por saberem que os seus supervisores investem no crescimento pessoal, pois através deles, os funcionários tendem a tê-lo como espelhos para melhor desempenho e também adquirirem conhecimento. Através desse questionário foi observado que os respondentes não têm apenas uma relação profissional, e isto faz com que os funcionários tenham sempre bons olhos para seus chefes.

\section{Conclusões}

Motivar pessoas parece ser uma tarefa fácil, no entanto, através deste estudo notou-se que motivar as pessoas não é simples como demonstrado, é necessário conhecer as pessoas de forma mais intrínseca e analisar os fatores externos como motivadores. Conclui-se que nesse estudo os trabalhos demonstram mais satisfação do que motivação, além disso, não possuem oportunidades de crescimento, foi constatado que uma parcela não sabe o que é um plano de carreiras, porque as empresas, como restaurantes não possuem devido ao número menor de funcionários. Desta forma, procuram manter apenas um ambiente de trabalho acessível, procurando melhorar as tarefas no trabalho no dia a dia. E a motivação vem a partir do momento em que sentem satisfação ao realizarem seus trabalhos com responsabilidade.

Foi encontrado dificuldades durante esta pesquisa, pois não foi possível coletar a totalidade de respondentes nos 3 restaurantes, porém os resultados obtidos revelaram o quanto é importante que os funcionários sejam motivados a buscarem além do que é lhe imposto como funcionário e como pessoa.

Como recomendação a pesquisa propõe que sejam feitas análises mais aprofundadas utilizando um quantitativo melhor de empresas no setor de food service, bem como, traçar profundamente o perfil motivacional dos funcionários.

\section{REFERÊNCIAS}

ALBUQUERQUE, L.A.C.S.; LUCENA, M.A.; SANTANNA, C.H.M.; GUIMARAES JUNIOR, D.S.; MELO, F.J.C. Teoria de Herzberg: Um Estudo de Caso em uma Escola Pública Municipal no Interior de Pernambuco. In: XXVI SIMPEP, Bauru- SP, 2019. 
BENDÔ, J. A. P. Políticas públicas para as MPEs: uma avaliação do Simples para Pernambuco. Dissertações de Mestrado - Economia/CAA, 2018.

BERGAMINI, C. W.; CODA, R. Psicodinâmica da vida organizacional. São Paulo: Pioneira, 1990.

CHIAVENATO, I. Gestão de pessoas: o novo papel dos recursos humanos nas organizações. Rio de Janeiro: Elsevier, 2014.

DOMINGOS JÚNIOR, A. P.; BARBOSA, M. A. C. Motivação no Setor Público: um estudo com servidores do município de Ponto Novo - BA. Revista Multidisciplinar e de Psicologia, Vol.10, n. 30, pp. 08-24. 2016.

FERNANDES, G. A. A. L. Dinâmica comportamental no setor público. Rio de Janeiro: FGV, 2014.

FONSECA, J. J. S. Metodologia da pesquisa científica. Fortaleza: UEC, 2002.

HERZBERG, F.; MAUSNER, B.; SNYDERMAN, B. The Motivation to Work. John Wiley and Sons, New York. 1959.

HERZBERG, F. One more time: How do you motivate employees? Harvard Business Review, 1987.

LO, L. Y. S., LIN, S. W.; HSU, L. Y. Motivation for online impulsing buying: A two-factor theory perspective. International Journal of Information Management. Vol 36, n. 5, pp. 759- 772, 2016.

KHALID, H. M. An empirical analysis of herzberg's two-factor theory. Niger J Manag Technol Dev. Vol. 4, n. 1, pp. 22-28, 2014.

KLEIN, F. A.; MASCARENHAS, A. O. Motivação no serviço público: efeitos sobre a retenção e satisfação profissional dos gestores governamentais. In: Anais ENANPAD, Rio de Janeiro, 2014.

MEDEIROS, D. D. A fuzzy model to evaluate the motivation to quality programs. International Journal of Computers, Vol. 3, pp. 230-237, 2009.

PERRY, J. L.; PORTER, L. W. Factors Affecting the Context for Motivation in Public Organizations. Academy of Management Review. Vol. 7, No. 1. pp. 89-9. 1982.

PONTES, B. R. Administração de Cargos e salários: carreira e renumeração, 17. ed. São Paulo: LTR, 2015.

ROBBINS, S. P. Comportamento Organizacional. 11. ed. São Paulo: Pearson Prentice Hall, 2005.

SEBRAE. (2018) Pequenos negócios em números, Disponível em: http://www.sebrae. com.br/sites/PortalSebrae/ufs/sp/sebraeaz/pequenos-negocios-emnumeros, $12 \mathrm{e} 8794363447510 \mathrm{Vg}$ nVCM1000004c00210aRCRD, acessado em: 22/11/2019.

TEJADA, J. Motivação e Liderança como Fatores Estratégicos do Sucesso: você pode fazer a diferença na organização. São Paulo: Educs, 2013.

YIN, R. K. Estudo de caso: Planeamento e métodos. Porto Alegre: Bookman, 2015 